\title{
Autologous mesenchymal stem cell therapy for progressive supranuclear palsy: translation into a phase I controlled, randomized clinical study
}

Rosaria Giordano ${ }^{1 *}$, Margherita Canesi ${ }^{2}$, Maurizio Isalberti ${ }^{3}$, Ioannis Ugo Isaias ${ }^{2,4}$, Tiziana Montemurro ${ }^{1}$, Mariele Viganò ${ }^{1}$, Elisa Montelatici ${ }^{1}$, Valentina Boldrin ${ }^{1}$, Riccardo Benti ${ }^{5}$, Agostino Cortelezzi ${ }^{6}$, Nicola Fracchiolla ${ }^{6}$, Lorenza Lazzari ${ }^{1}$ and Gianni Pezzoli ${ }^{2}$

\begin{abstract}
Background: Progressive Supranuclear Palsy (PSP) is a sporadic and progressive neurodegenerative disease which belongs to the family of tauopathies and involves both cortical and subcortical structures. No effective therapy is to date available.

Methods/design: Autologous bone marrow (BM) mesenchymal stem cells (MSC) from patients affected by different type of parkinsonisms have shown their ability to improve the dopaminergic function in preclinical and clinical models. It is also possible to isolate and expand MSC from the BM of PSP patients with the same proliferation rate and immuphenotypic profile as MSC from healthy donors. BM MSC can be efficiently delivered to the affected brain regions of PSP patients where they can exert their beneficial effects through different mechanisms including the secretion of neurotrophic factors.

Here we propose a randomized, placebo-controlled, double-blind phase I clinical trial in patients affected by PSP with MSC delivered via intra-arterial injection.
\end{abstract}

Discussion: To our knowledge, this is the first clinical trial to be applied in a no-option parkinsonism that aims to test the safety and to exploit the properties of autologous mesenchymal stem cells in reducing disease progression. The study has been designed to test the safety of this "first-in-man" approach and to preliminarily explore its efficacy by excluding the placebo effect.

Trial registration: NCT01824121

Keywords: Progressive supranuclear palsy, Parkinson's disease, Mesenchymal stem and stromal cells, Advanced therapy medicinal products, Cellular therapy

\section{Background}

Progressive supranuclear palsy (PSP) is a rare form of parkinsonism with a prevalence of about 0.5 cases per 100,000 inhabitants and with an incidence of 5.3 new cases every 100,000 inhabitants [1,2]. Its etiology is unknown. From a pathological point of view, the disease consists in a neurodegenerative process that involves the basal ganglia, the brainstem, the prefrontal cortex and the cerebellum, with accumulation of a tau protein - hence

\footnotetext{
* Correspondence: rosaria.giordano@policlinico.mi.it

'Cell Factory, Unit of Cell Therapy and Cryobiology, Fondazione IRCCS Ca' Granda Ospedale Maggiore Policlinico, Milano, Italy

Full list of author information is available at the end of the article
}

the classification as tauopathy [3]. Onset typically occurs after 40 years of age. The symptoms include bradykinesia, proximal and axial rigidity and early postural instability. The key sign, which gives the disease its name, is the supranuclear paralysis of vertical gaze, followed by abnormalities of horizontal gaze. This sign usually appears three or four years after the onset of motor symptoms. The most disabling symptoms, especially in the early phases of the disease, are stiff, upright posture and abnormal gait with a very broad base associated with severe postural instability and frequent falls, especially backwards. The patient is confined to a wheelchair on average after 5 years of disease. Levodopa response is poor or absent

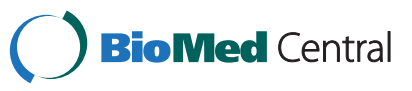


[4-6]. Mean survival amounts to 7 years [7]. Early falls, speech and swallowing problems, diplopia and early insertion of a percutaneous gastrostomy are predictors of reduced survival [8].

The differential diagnosis between PSP and the other parkinsonisms is made according to clinical criteria [9]. Molecular biology studies have shown that the parkinsonisms share a common pathogenesis, namely the intraneuronal accumulation of misfolded proteins that cannot be removed normally. The misfolding is caused by structural abnormalities due to genetic mutation and/or exposure to environmental factors [10]. The syndromes have been classified according to the kind of misfolded proteins that accumulate: synucleinopathies, in which the main accumulated protein is alpha-synuclein, and tauopathies, in which it is protein tau [11]. Unfortunately the greater understanding of the parkinsonisms in terms of molecular biology has not resulted in the finding of a cure. At present all these movement disorders are incurable. However, symptomatic treatment is available. It consists mainly in dopaminergic treatment (levodopa and dopamine agonists), which controls symptoms for several years in Parkinson's Disease (PD), whereas the response is generally poor and short-lived in the other syndromes [12]. Moreover, even in PD it is not effective on the most disabling symptoms, such as postural instability and freezing. Also surgical treatment is available. It consists in the implantation in strategic positions of electrodes for deep brain stimulation, which corrects electrical circuit imbalances occurring in circumscribed parts of the brain in PD patients $[13,14]$. However, this treatment is not suitable for the other syndromes, in which the neurodegenerative process is more extensive and general conditions deteriorate more rapidly.

\section{Summary of pre-clinical data to support the use of autologous MSC in PSP patients}

Mesenchymal stem cells (MSC) are multipotent cells that can be isolated from many sources, including bone marrow (BM). Besides their in vitro and in vivo potential to transdifferentiate into several mesodermal lineages, their therapeutic relevance is mostly due to their immunosuppressive and anti-inflammatory properties [15]. Other paracrine actions of MSC have been claimed to act in several animal models of diseases and also in preliminary clinical trials [16-18]. Indeed, the real MSC transdifferentiation capacity seems to have limited clinical relevance, with the exception of bone differentiation that is currently exploited in different orthopaedic trials [19]. The main expected pharmacological effect of BM MSC on dopaminergic neurons that support their use in PSP is the potential to regulate cell differentiation and function by reducing oxidative stress and apoptosis. Regarding this potential mechanism of action, there are several experimental evidences of the neurotrophic effect of MSC that result in the reduction of tissue damage and neuronal loss. The brain derived neurotrophic factor (BDNF) and the glial derived neurotrophic factor (GDNF) have been recently identified as the putative mediators of this effect. BDNF is a protein belonging to the neurotrophine family that promotes neuronal growth, differentiation and survival in different areas of central and peripheral nervous system. The molecular pathway that mediates the BDNF effects on cell survival is well known and documented [20]. Briefly, the homodimeric BDNF induces the dimerization of the thyrosin-kinase receptor $\mathrm{B}$, the binding of ATP to the intracellular ATPbinding loop, and in turn the stimulation of the kinase activity. The autophosphorylation of the tyrosine triplet in the kinase domain is a prerequisite for further phosphorylation steps (via Src homology 2/collagen-related protein and PIK3and MAPK pathways) that finally mediate the effects of the neurotrophin on neuronal survival, differentiation, and gene expression as well as acute effects on synaptic transmission [21].

Also the molecular basis of GDNF mechanism of action is well know and consists essentially in its interaction with the GDNF-family receptor-alpha (GFRa1), on the activation of the Ret tyrosine-kynase [22] and on the PLC $\gamma$, PI3/ Akt and MEK-ERK1/2 pathway [23]. Nevertheless, it is also known that the GDNF- GFRa1 complex can work independently from Ret activation by activating the Src family and consequently the c-AMP-response element binding protein (CREB) [24,25]. All these mechanisms have a central role in regulating the survival of dopaminergic neurons [26]. The precise balancing of these signals results in the definition of neuronal cell fate in response to different noxa.

In order to establish the role of the hypothesized mechanism of action, the ability to synthesize and secrete BDNF and GDNF by MSC from PSP patients and healthy donors has been evaluated, by real-time PCR and by ELISA. The results are shown in Figure 1 and they demonstrate that MSC from PSP are able to produce as main neurotrophine as MSC from healthy donors. For that reason, BDNF and GDNF secretion from MSC will be measured during the clinical protocol as potency assay. The use of cells instead of the simple administration of synthetic proteins has several advantages. First of all endogenously produced neurotrophines are in principle fully bio-available since MSC could be able to vehicle directly the neurotrophines to the damaged tissue. In this regard, it has been already demonstrated that MSC are able to overcome the brain-blood barrier $[27,28]$. MSC may also act by releasing extracellular vesicles, including exosomes and microvescicles, which transport lipids and different mRNA functional transcripts, microRNA, long non-coding RNA and occasionally genomic DNA and therefore they could 

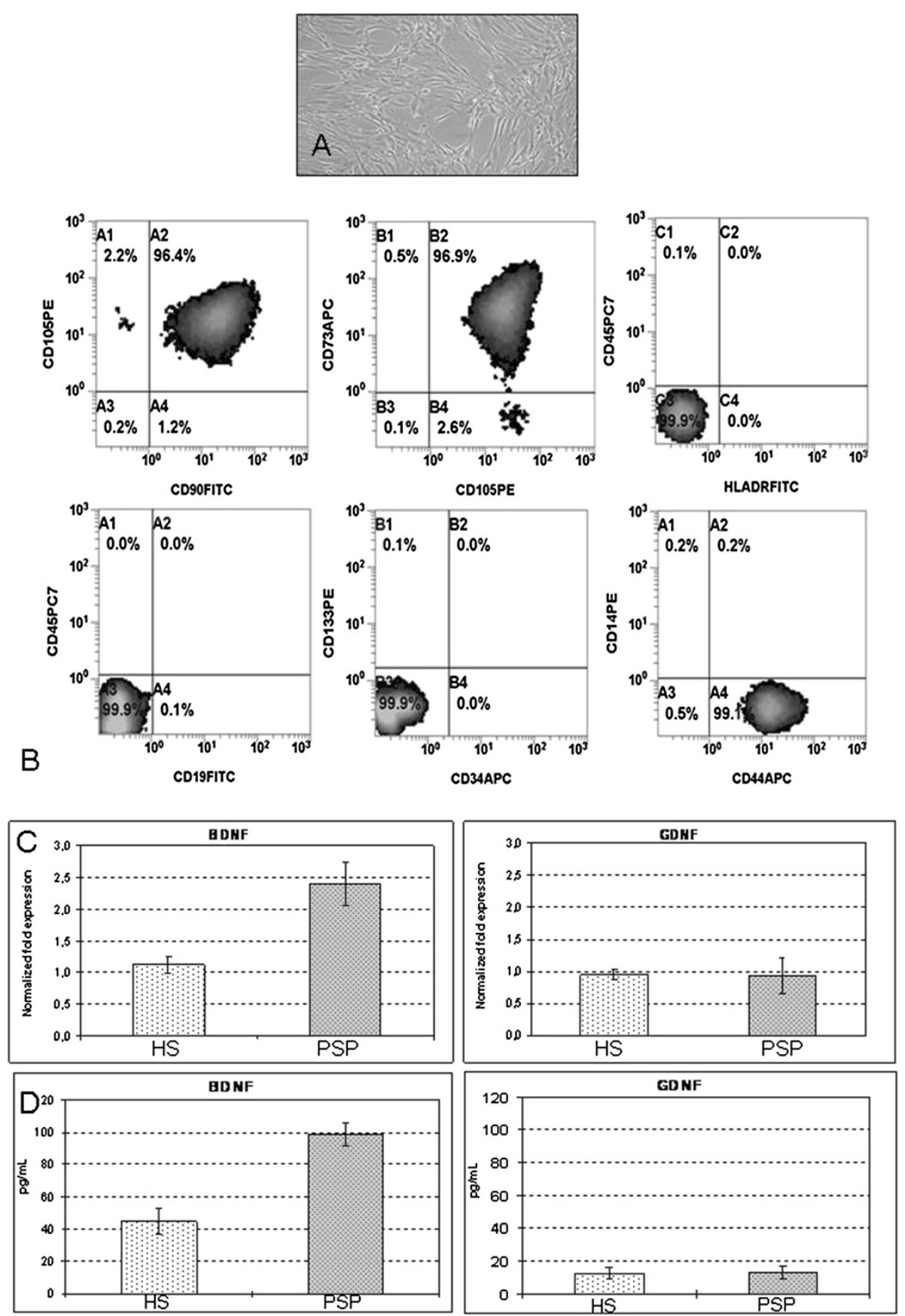

Figure 1 Pre-clinical data. Bone marrow mesenchymal stem cells from patients affected by progressive supranuclear palsy have the typical spindle-shaped morphology (A), are positive for mesenchymal-specific antigens to an extended flow-cytometric analysis (B) and express BDNF and GDNF as those from healthy subjects, as demonstrated by real time PCR (C) and ELISA (D). BM MSC: bone marrow mesenchymal stem cells; PSP: Progressive Supranuclear Palsy; HS: healthy subjects. The results of flow cytometric analysis, Elisa and PCR are expressed as mean ( \pm SD).

be able to transfer genetic information that may induce transient or persistent changes in the recipient cells [29].

\section{Methods/design}

The current trial is a prospective, randomized, shamcontrolled, phase I clinical study to evaluate the safety and efficacy of autologous mesenchymal stem cell intra-arterial infusion in patients with PSP. The protocol has been authorized by the local Ethics Committee of Fondazione IRCCS Ca' Granda Ospedale Maggiore Policlinico of Milano, Italy, and by the National Competent Authority for phase I cell therapy protocol at Istituto Superiore di Sanità. 


\section{Primary and secondary objectives}

The primary objective is to assess the safety of autologous MSC therapy in patients with PSP in a "first-in-man" context.

The secondary objective is to assess the efficacy of autologous MSC therapy in patients with PSP in terms of stabilization or improvements in motor function, neuropsychological parameters and neuroimaging findings.

\section{Exploratory objectives}

Exploratory objectives will help to identify the mechanisms underlying the effect of MSC on neurodegeneration. Whit this aim, the ability of MSC to in vitro rescue 6OHDA damaged neural cell lines and to synthesize and secrete neurotrophines will be measured to determine if these factors are related to the clinical response.

\section{Study design}

All patients over the age of 40 years with diagnosis of “probable progressive supranuclear palsy - Richardson's disease subtype" according to current diagnostic criteria [4; 9] are eligible (Table 1).

The first 5 patients are treated in an open phase with autologous MSC therapy with the same procedures as for the randomized phase.

After these first 5 patients have been followed-up for a minimum of 2 months from the cellular infusion, the ISS Data Safety Monitoring Board will review the safety data prior to open the accrual of the subsequent randomized controlled phase.

In the randomized phase the patients undergo to:

- immediate autologous MSC therapy followed by delayed sham or

- immediate sham followed by delayed autologous MSC therapy.

The delay amounts to 6 months and all patients will be followed-up for at least 12 months after MSC therapy, so the total duration of the study is 18 months. The study design is shown in Figure 2.

\section{Bone marrow collection and MSC isolation}

Bone marrow is aseptically drawn by qualified medical staff at the Bone Marrow Transplantation Centre - Fondazione IRCCS $\mathrm{Ca}^{\prime}$ Granda Ospedale Maggiore Policlinico Milano according to standard procedures. The maximum quantity of bone marrow to be collected is $30 \mathrm{ml}$. The isolation of BM MSC is performed under Good Manufacturig Practices (GMP) conditions as requested by European Regulations for cell-based advanced therapy medicinal product (ATMPs) in the "Cell Factory" Laboratory of Fondazione IRCCS Ca' Granda Ospedale Maggiore Policlinico Milano. The "Cell Factory" was the first public Italian hospital-based facility to receive authorization for the production of ATMPs (Agenzia Italiana del Farmaco - AIFA - authorization n'120/2007 and subsequent confirmations, the last in 2013). The procedures for BM MSC aseptic production and quality control have been developed by the authors. Briefly, unprocessed BM is directly seeded in alpha Modified Eagle Medium supplemented with 10\% FBS at the concentration of 50,000 total nucleated cells $(\mathrm{TNC}) / \mathrm{cm}^{2}$ in Cell Stack Chamber system (Corning, Lowel, MA). After 72 hours, non-adherent cells are removed by washing with PBS (Macopharma, Mouvaux, France) with complete medium change. Medium changes are also performed twice a week. On day $14( \pm 3)$ MSC at P0 are detached using $25 \mathrm{~mL} /$ layer of TrypLE- Select (Gibco-Life Technologies, Carlsbad, CA, USA) and re-seeded in the same culture conditions at the concentration of $4000 \mathrm{MSCs} /$ $\mathrm{cm} 2$. The culture is stopped at 28 days $( \pm 3)$ of culture (passage 2) and the cells are re-suspended in a solution containing normal saline solution with human serum albumin (Kedrion, Castelvecchio Pascoli, Lucca, Italy) 10\% (vol:vol) and DMSO (Bioniche Lifesciences, Inc., Belleville, ON, Canada) 10\% (vol:vol). The cell product is cryopreserved using a controlled-rate freezer (Nicool Plus, Air Liquide) programmed to freeze at $-1 \mathrm{C} / \mathrm{min}$ and is stored in the vapor phase of liquid nitrogen in bags (CryoMACS Miltenyi, Teterow, Germany). The day of the infusion, the cells are thawed at $37^{\circ} \mathrm{C}$ and resuspended (1:2) in normal saline solution with human serum albumin (Kedrion) 10\% (vol:vol) and ACD-A 12\% (Fresenius Kabi, Bad Homburg, Germany). Finally, volume is adjusted to $200 \mathrm{~mL}$ with normal saline solution alone.

\section{Administration of MSCs}

Patients undergo neuroleptoanalgesia and are monitored by an anesthesiologist. MSCs are administered by intraarterial route, as already described [28], with modifications according to local equipment and local standards: with Seldinger technique, catheterization is carried out via the right common femoral artery (or the left one in the event of difficulty in achieving arterial access) using a 6 F Ultimum EV (St Jude Medical, Minnetonka, MN, USA) introducer and a 5 F Hinck or Simmons (Terumo Europe NV, Leuven, Belgium) diagnostic catheter. An angiographic study of the cervical and intracranial arteries is performed, with the support of a $0.035 \mathrm{inch}, 150 \mathrm{~cm}$ long hydrophil guide (Terumo Europe NV, leuven, Belgium). Subsequently, with or without an exchange maneuver, using a $260 \mathrm{~cm}$ Starter exchange (Boston Scientific, Natick, MA, USA), a Mach $190 \mathrm{~cm}$ catheter guide (Boston Scientific, Natick, MA, USA) is used, after intravenous administration of a bolus of heparin sodium (3,000 to 5,000 IU according to body mass) to reduce the risk of thromboembolism. The catheter guide will be positioned in the widest vertebral artery. 
Table 1 Inclusion and exclusion criteria

Inclusion criteria

Exclusion criteria

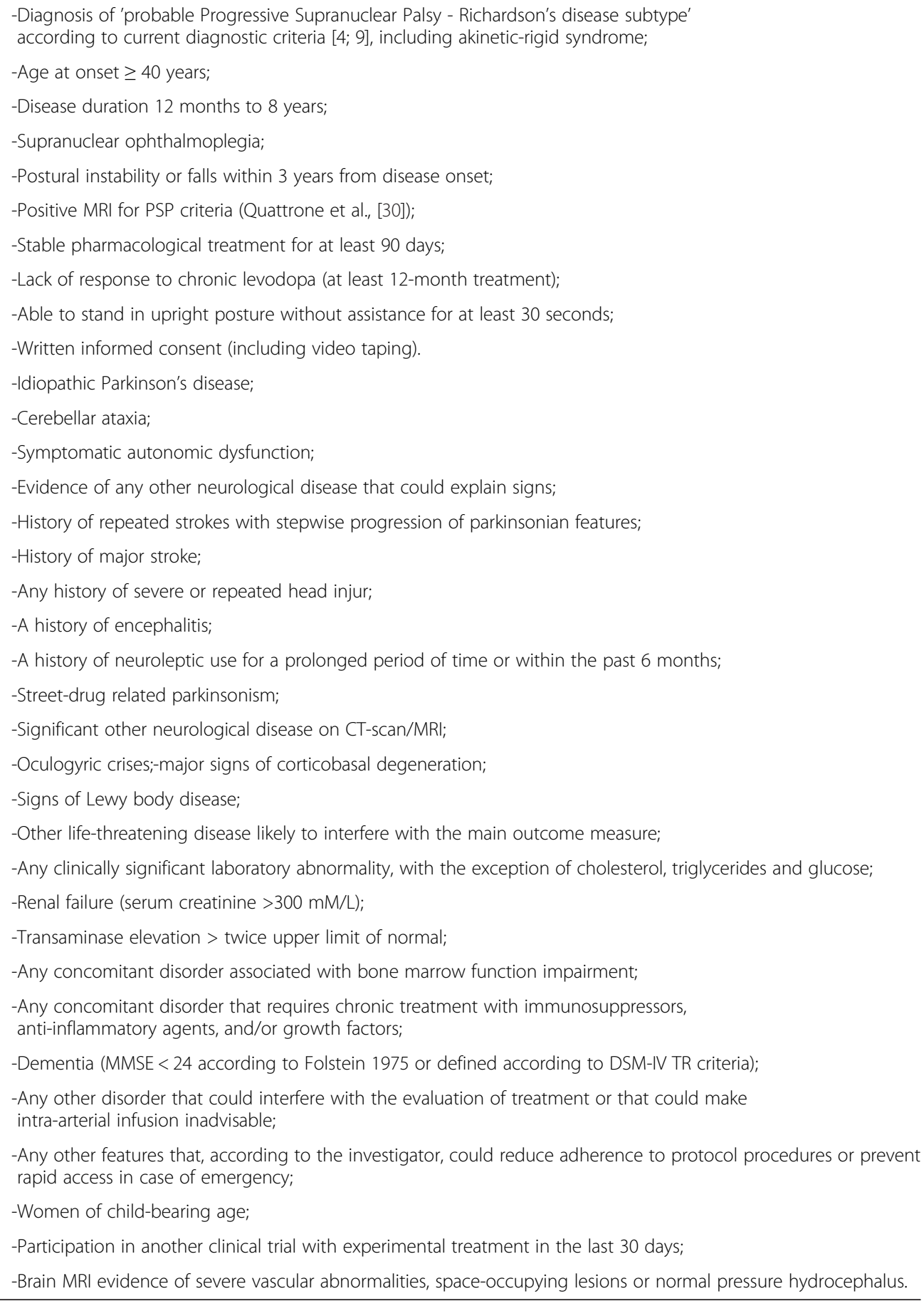

Subsequently, the main catheter is placed in both internal carotid arteries and a microcatheter is moved forward up to the widest vertebral artery.

The MSC are then injected into the various districts with an automated peristaltic pump, via the microcatheter. Should any ulcerated atherosclerotic plaques be found at carotid bifurcations, therapy is injected proximally to the lesion. Once therapy administration has been completed, MRI of the brain is performed with two sequences, FLAIR and DWI. Patients are closely monitored for 3 hours after the procedure and then moved to the Neurosurgery Unit, where they spend the next 24 hours. Provided that the procedure was uneventful, they are discharged the day after the cell injection. Patients undergoing the sham procedure are monitored in the same way. 


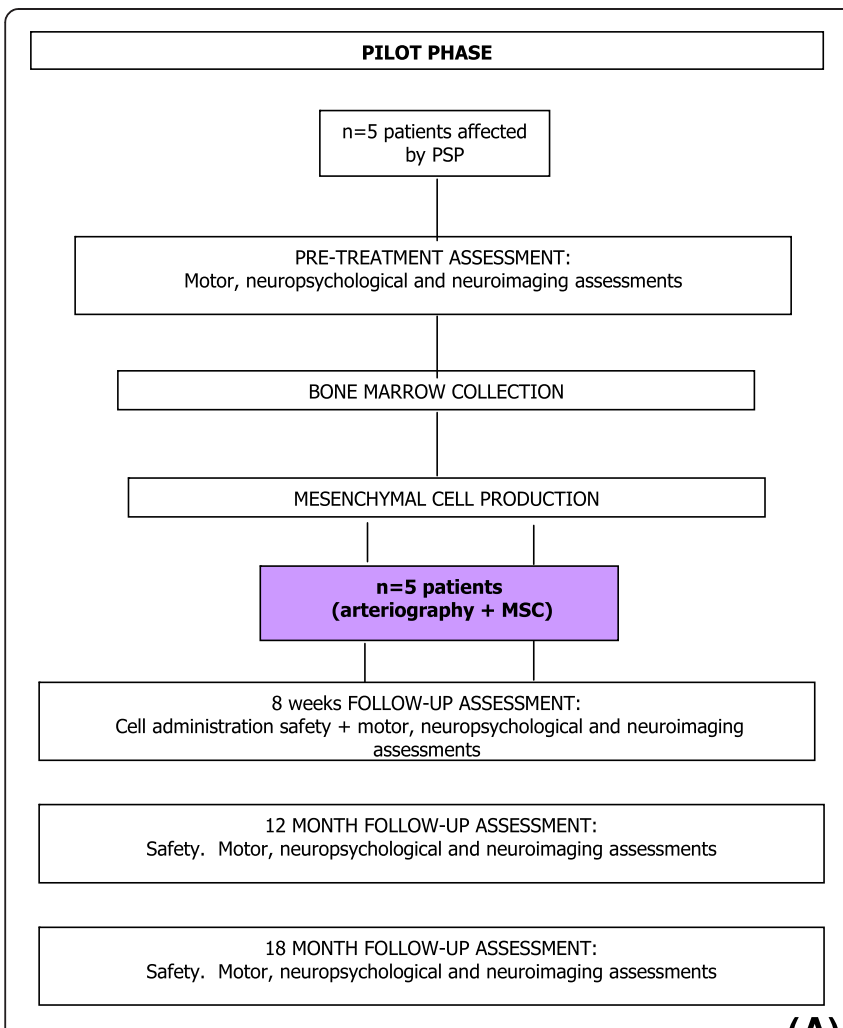

(A)

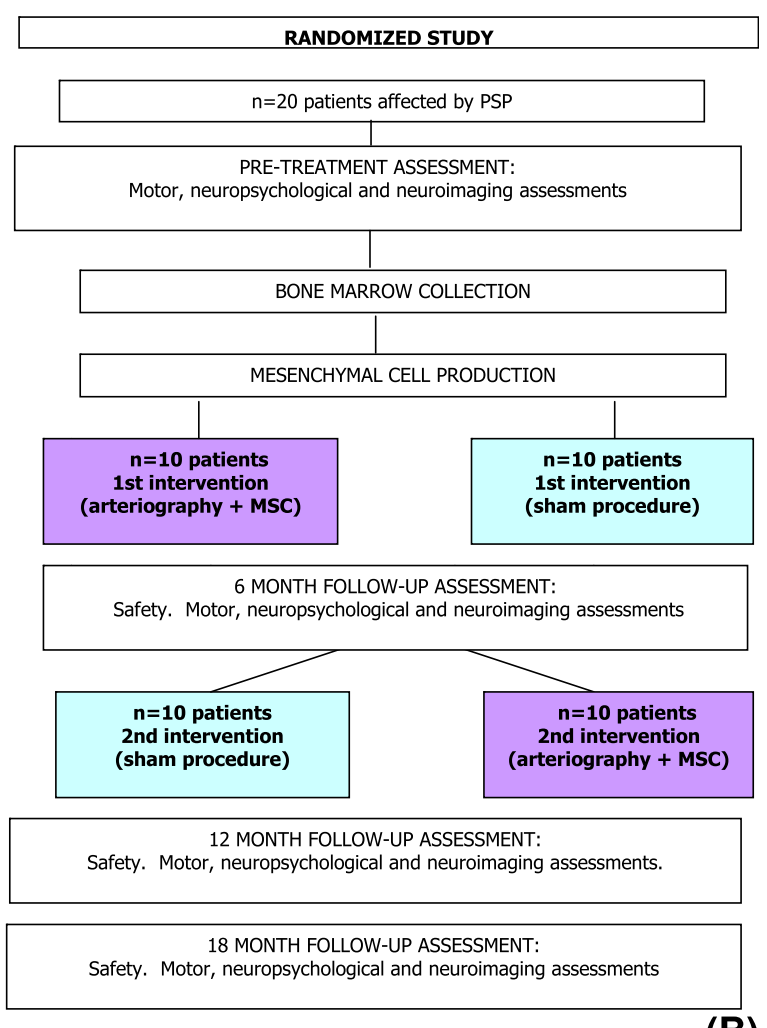

(B)

Figure 2 Study design. A) Pilot phase; B) Randomized study.

\section{Motor status assessment}

The patients undergo neurological examinations designed to assess motor function using the following scales:

Unified Parkinson's Disease Rating Scale (MDS-

UPDRS) total and motor score [31];

Hoehn and Yahr staging [32];

PSP rating scale [33] to specifically rate PSP severity;

SEADL (Schwab England Activities of Daily Living);

CGI (Clinical Global Impression for disease severity) [34];

If the patient is taking dopaminergic therapy, the neurological assessment is performed twice: in OFF upon wakening and in 'ON' after taking therapy in the morning by the same neurologist.

After patient's consent, the entire neurological examination is video-recorded so that the evaluation can be performed again by assessors blind to allocation.

\section{Multifactorial movement analysis}

Patients perform four tasks:

(1.) upright standing;

(2.) starting to walk;

(3.) linear free gait (with and without a cognitive task);
(4.) gait along a curvilinear trajectory.

Tests are carried out in the order listed above as already described with minor modifications [35], if possible given the clinical status of the patient, before and after MSC therapy. Each test requires 4-8 walks, at intervals of about 5-10 minutes, on a platform about 10 meters long at a comfortable speed. The cognitive task consists in a calculation (counting backwards, starting from 100 and subtracting 7 at a time). The patients are not corrected or stopped if they make mistakes in calculating. The curvilinear test consists in straight walking for 2 meters towards the center of the platform and then a curvilinear trajectory with an angle of $90^{\circ}$ for another 2 meters. Data are collected with a SMART optoelectronic movement analysis system (BTS SpA, Italy) equipped with: (i) optoelectronic system (six cameras with $60 \mathrm{~Hz}$ acquisition frequency) to establish the position of 29 reflecting markers applied onto the skin of the patients at anatomical landmarks (ii) three dynamometric platforms (KISLER, GmbH, Winthertur, Switzerland) with $960 \mathrm{~Hz}$ acquisition frequency to record ground reaction forces; (iii) TELEMG telemetric electromyograph (BTS SpA) and a FreeEMG wireless electromyography to measure muscular activity of tibialis anterior and soleus bilaterally. 


\section{Neuropsychological assessment}

The following tests are performed:

- Mini Mental State Examination (MMSE) [36]

- Neuropsychological measures: verbal comprehension; perceptual organization, immediate memory (story, design, word list learning), delayed memory (story, design, word list recall), word list recognition, language (confrontation naming, category fluency, letter fluency, auditory comprehension), attention/concentration, visuospatial ability (block design), processing speed, executive functioning (cognitive flexibility).

\section{Quality of life}

Quality of life is assessed by asking the patients to fill-in the PDQ-8 questionnaire [37] at baseline, and 6 and 12 months after MSC therapy.

\section{Neuroimaging}

All patients perform a longitudinal neuroimaging assessment at baseline and 6,12 and 18 months after MSC therapy, using striatal dopamine transporter Single Photon Emission Computed Tomography (SPECT) and Positron Emission Tomography (PET) using a tropanic tracer labeled with Iodine-123 (FP-CIT) for SPECT imaging and Iodine-124 (Beta-CIT) for PET/TC imaging. SPECT studies are carried after intravenous administration of 110-140 MBq of ${ }^{123}$ I-FP-CIT (Datscan ${ }^{\circ}$, GE-Health, Amersham, UK) performed 30-40 minutes after thyroid blockade (10-15 $\mathrm{mg}$ of Lugol solution per os) in all subjects. ${ }^{18} \mathrm{~F}$-fluorodeoxyglucose positron emission tomography (FDG-PET/TC) is performed 4-6 hours and 20-24 hours after intravenous injection of $18-30 \mathrm{MBq}$ of ${ }^{124} \mathrm{I}$ - Beta-CIT. All patients undergo ${ }^{18}$ F-fluoro-2-deoxy-D-glucose positron emission tomography scanning (FDG-PET) at rest, after intravenous injection of 285 to $296 \mathrm{MBq}$.

\section{Safety}

Toxicity is evaluated following the National Cancer Institute Common Toxicity Criteria Manual (CTCAE v 4.0) [38]. At screening demographic information, medical history and specific history of PSP (age at onset, signs and symptoms, previous investigations, with particular reference to neuroimages, treatment) are collected. Patients are monitored closely after the MSC/sham procedure for 3 hours at the day-hospital of the Diagnostic and Interventional Neuroradiology Unit and subsequently at the ward of the Neurosurgery Unit until discharge the next day. A general medical examination and routine laboratory tests are performed at every visit, plus any further investigations that are deemed necessary according to the findings of the general medical examination.

\section{Statistics}

\section{General considerations}

As noted above, the safety of cellular therapy administration in the first five patients will be reviewed by the Data Safety Monitoring Board. These reviews will be shared with our institutional IRB. If the treatment appears safe, as determined by the Data Safety Monitoring Board with institutional IRB agreement, the protocol may be reopened to treat a total of 20 patients.

For statistical analysis of efficacy endpoints, descriptive statistics are computed for variables of interest (mean and $\mathrm{SD}$ for continuous variables and frequencies for categorical variables). Test results are summarized over time using appropriate graphical or tabular formats. The non parametric pair wise Wilcoxon rank sum test will be used to investigate each variable within subject and between the same subject at different follow-up (e.g. pre- vs. post-MSC, pre- vs. postsham, etc.). The use of a non-parametric test has been considered the most appropriate since the distribution of the variable is not known and the number of observations is relatively small. For each time point, the test will be performed with 20 paired values (the values before and after MSC therapy in the 10 subjects allocated to immediate treatment plus the 10 subjects allocated to the delayed treatment).

P-values $<0,05$ will be considered statistically significant. Additional summary statistics are also considered as appropriate to the data.

\section{Safety data}

A descriptive analysis of all AEs and ADRs will be provided.

The tabulations of laboratory data will be provided together with the normal ranges of the laboratory, highlighting any values that are out of range.

\section{Motor function}

A descriptive analysis of the course of the main endpoints will be provided:

- change in total, ADL, motor and part IV UPDRS score;

- change in Hoehn \& Yahr stage;

- change in PSP rating scale (cognitive disturbances, bulbar functions, limb function, ocular motor function);

- change in SEADL;

- CGI score.

\section{Multifactorial movement analysis}

The data related to each of the four tests will be normalized and the mean of the values related to each variable recorded during the 8 walks will be calculated. The data before and after MSC therapy will be compared using Wilcoxon's signed rank test for matched pairs, considering 
the patients before and after treatment as a pair (the results at each follow-up visit will be assessed separately). Moreover, the results obtained in PSP patients will be compared with those obtained in the group of agematched healthy volunteers using the non-parametric Mann-Whitney U Test.

\section{Neuropsychological assessments}

A descriptive analysis of the course of the main endpoints (change in each of the test scores vs baseline will be provided).

\section{Neuroimaging assessment}

The main neuroimaging parameter will be:

- specific striatal uptake of the labeled ligand for SPECT analysis; this parameter measures the striatal density of dopamine transporters

- normalized labeled ligand subcortical and cortical uptake for PET analysis; this parameter measures normalized regional cerebral flow/glucose metabolism in the gray matter of the brain.

The analysis will be performed using ANOVA to assess changes in cerebral volume by SPM software. Significance will be set at $\mathrm{p}<0.01$.

\section{Translational endopoints}

\section{In vitro model of tissue damage and repair}

In our laboratory we set up an in vitro assay to assess the effect of MSC on neural cell damage and repair. Human neuroblastoma cell line SK-N-BE, cultured in appropriate medium, is damaged using 6-OHDA. After 24 hours, the cells are washed and MSC from PSP patients and, in parallel, from healthy subjects are added in no-contact co-culture using Transwell ${ }^{\circ}$ Permeable supports. At different time points $(0,48,72$ and 144 hours $)$ the viability of SK-N-BE cells is checked by quantification using 3-(4,5-dimethylthiazole-2yI)-2,5-diphenyltetrazolium bromide (MTT assay). In addition, at all the above defined time points, the supernatant are collected and stored at $-80 \mathrm{C}$ for the ELISA quantification.

\section{Neurotrophine produced by MSC}

In order to investigate the role of neurotrophines secreted by autologous MSC from PSP patients as mediators of their neuro-rescue potential, the production of multiple neurotrophic factors will be evaluated throw a multiplex sandwich ELISA (matrix metalloproteinase 2/3/9/13 MMP 2/3/9/13; BDNF; GDNF; neurotrophin 3 - NT-3; basic nerve growth factor - BNGF, ciliary neuronotrophic factor - CNTF) on MSC supernatants and a quantitative RT-PCR analysis (for BDNF and GDNF) on MSC RNA extract.

\section{Innovation}

The proposed first-in-man study has several innovative characteristics. First, we demonstrated that it is possible to produce an advanced therapy medicinal product, manufactured in compliance to GMP rules from the bone marrow of patients affected by PSP and that this product has the same safety profile as that produced from healthy donors. Second, we translated the concept of using MSC as a cell-based delivery system not only for neurotrophic factors, but also for different types of nucleic-acid-containing vesicles, able to transiently or permanently transfer genetic information to the surrounding cells. Moreover, the presented study aims to document the putative effect of cell therapy by combining clinical evaluation and multifactorial movement analysis. We have therefore established a multidisciplinary platform to study the effect of cell-based advanced therapy that can be applied not only to PSP patients, but also to other neurodegenerative disorders (e.g. MSA, PD, etc.).

\section{Discussion}

Cell-based advanced therapy is a novel and extremely promising option to cure otherwise untreatable neurodegenerative diseases but there are still several bottle necks that slow the progression and the widening of clinical trials in this context. Mainly, despite the overall positive results reported in several small studies in PD and MSA, there is a lot of uncertainness regarding the real capacity of MSC to reach the brain, the selectivity of their targets and their real mechanism of action. Moreover, in PD as well as in atypical parkinsonisms no validated biomarker is available to follow-up the neuroprotective effect of putative disease-modifyng treatments. So, why are we performing this trial? First: there are several positive results in other no-option parkinsonisms as well as in PD that deserve to be confirmed also in other pathologic context like PSP. Therefore, even thought the primary objective of this protocol is to demonstrate the safety of autologous MSC intra-arterial administration in subjects affected by PSP, we have designed a sham-controlled study, with the aim to document efficacy as well. Second, we would like to indirectly get information on the putative neuroprotective mechanism of action of MSC in PSP by comparing the in vitro results of the proposed potency assay and the clinical outcome. The biological hypothesis underlying the rationale of the proposed protocol is that MSC can reduce the neural cell loss in PSP by reducing cell apoptosis and the detrimental consequence of oxidative stress on neural cell homeostasis. Whit this premises, it should be clear to the reader that, the objective of making neurons from stem cells is out of the scope of our approach. Nevertheless, the story of replacing lost neurons in parkinsonisms by transplantation has been pursued for years. At first tissue was transplanted. In 
the 1980s autologous adrenal gland medullary tissue was transplanted first in animals and then in humans. Significant clinical improvements were achieved, but common and even serious postoperative complications induced clinicians to abandon this option [39-44]. In the 1990s non-autologous fetal neuron transplantation was attempted. Clinical benefits were modest and confined to younger patients ( $<60$ years), and complications occurred i.e. the appearance of postoperative dyskinesias that in a few cases were severe and refractory to treatment. PET investigations suggested that these cases were due to an imbalance in the dopaminergic circuits induced by the transplanted cells $[45,46]$. Recent in vivo brain imaging findings in two patients, who had exhibited major motor recovery after transplantation, suggested that the cause of the dyskinesias was a serotonergic hyperinnervation [47]. An alternative explanation is that an immune response was responsible for both the appearance of dyskinesias and the modest extent of the therapeutic benefits [48]. Furthermore, the autopsies of subjects who had received fetal mesencephalic dopaminergic neurons disclosed the presence of Lewy bodies, raising the possibility of host-to-graft disease propagation. Thus, the prospects for dopaminergic fetal neuron transplantation in PD do not appear to be promising [49]. Autologous stem cell transplantation has been proposed for the most common form of parkinsonism, PD [50]. This proposal overcomes the ethical reservations related to the use of fetal cells or embryonic stem cells, and removes the risk of transplant rejection. Even thought the ability of different bonemarrow derived stem cells to migrate into the brain and to differentiate into cells bearing neural markers have been postulated even in vivo [51-53], the proven evidence of the so-called neural plasticity have never been demonstrated. Indeed, in the last years the attention of most investigators has been addressed to study the potential of BM mesenchymal stem cells to positively influence neural cell survival and to reduce cell apoptosis [54-56]. MSC have proved to be able to produce different kinds of growth factors that increase neuronal survival, to possess immunoregulatory properties able to influence inflammatory conditions and to migrate to damaged tissue areas where they might contribute to counteract neurodegeneration. What is more, they can be easily harvested from the bone marrow of the patients, easily expanded on a large scale for autotransplantation, and administered to patients via various routes [57]. MSCs have been isolated from PD patients and they do not differ from those of healthy subjects in terms of phenotype, morphology and ability to differentiate [58]. Furthermore, it has been demonstrated that MSCs exert neuroprotective effects on dopaminergic neurons both in vitro and in animal models of PD (rats given the toxin MG-132 or 6-OHDA), mediated by anti-inflammatory activity and the secretion of growth factors [59-62]. Of particular interest is the fact that in the rats given MG-132, a proteasome inhibitor, MSCs also reduced the accumulation of polyubiquinated proteins, a finding that suggests that they also contribute to correct proteasome dysfunction, which is believed to play an important role in the pathogenesis of PD [60].

Autologous MSC therapy would therefore appear to be an important candidate for the development of a parkinsonism-modifying therapeutic strategy.

To our knowledge, four pilot clinical trials have been published on the use of autologous stem cell transplantation in patients with primary parkinsonism. Two studies $[63,64]$ have been conducted in patients with multiple system atrophy (MSA). The first one was an open-label, controlled trial designed to assess the feasibility and safety of MSC therapy by intra-arterial and intravenous route in which eleven MSA patients were infused MSC therapy through the internal carotid artery and the proximal portion of the vertebral artery once and by intravenous route thereafter once a month for three months. Treated patients were compared to 18 untreated control MSA patients. Follow-up was continued up to one year after the beginning of treatment and consisted in neurological examinations using the unified MSA rating scale scores (UMSARS). In addition, 5 treated patients and 10 untreated patients underwent brain metabolism imaging using PET and ${ }^{18}$ F-fluoro-deoxyglucose (FDG). After 12 months mean total UMSARS score was similar to the score at baseline in the treated group (functional stabilization), whereas it had worsened in the control group $(p=0.002)$. Moreover, treated patients showed increased brain metabolism by means of FDG-PET, while the untreated group had decreased uptake. The most significant adverse events reported was the occurrence in 7 patients of small spotty lesions on MR images that were considered to be asymptomatic microemboli, a frequent complication of catheterization techniques. The same group recently published the results of a second protocol, in which thirty-three patients with probable MSA-C were randomly assigned to receive MSC via intraarterial and intravenous routes or placebo. The primary outcome was change in the total UMSARS scores from baseline throughout a one-year follow-up period between groups. In this study, the MSC group had a smaller increase in total and part II UMSARS scores compared with the placebo group. Cerebral glucose metabolism and gray matter density were more extensively decreased in the cerebellum and the cerebral cortical areas, along with greater deterioration of frontal cognition in the placebo group compared with the MSC group. No serious adverse events directly related to MSC treatment were recorded. However, intra-arterial infusion resulted again in small ischemic lesions on MR. In another open-label clinical trial [65], autologous BM MSCs were transplanted 
into a sublateral ventricular zone of the brain by stereotaxic surgery in 7 male patients aged 22 to 62 years with advanced PD. The diagnosis was based on the presence of the classical symptoms and a good response to levodopa. The patients were followed up for 10 to 36 months. Three of the patients experienced motor improvement compared to baseline; the mean extent of improvement in UPDRS score was $22.9 \%$ in OFF and $38 \%$ in ON. Two of the patients were able to reduce the dosage of their antiparkinson medications. No serious adverse events occurred. MRI imaging did not disclose any significant changes. The last study [28] was an open-label clinical trial conducted by interventional radiologists, who subjected 53 patients with a diagnosis of PD made according to UK Brain Bank criteria to intraarterial autologous implantation of mononuclear cells from bone marrow. The cells were introduced by intraarterial catheterization, infusing the cells into the posterior part of the circle of Willis, from which the perforating arteries that irrigate the basal nucleus and the substantia nigra originate. Four patients received a second implant. None of the patients had major complications. They experienced major significant changes in median disease severity scores: UPDRS, Hoehn \& Yahr, Schwab \& England and Northwestern University Disability Scale (NUDS). In eight patients follow-up MR spectroscopy revealed mean improvements in n-acetylaspartate/creatine ratio. These studies demonstrated the feasibility of autologous cell transplantation in patients with parkinsonism, but they did not demonstrate efficacy, because their design did not ensure objective measurements. Also, clinical improvement could have been influenced by the beliefs of patients and investigators alike as they were open-label studies. Neuroimaging changes could not be easily dismissed, but they were available only in a few patients and did not focus on the kind of damage that is seen in parkinsonism. A search in the WHO worldwide clinical trial database on August 1, 2013 disclosed 390 studies assessing MSC therapy. Out of these only other three studies are ongoing in patients with Parkinson. To our knowledge this is the first time that autologous MSC therapy is given to PSP patients.

In this kind of cell therapy protocols, a crucial question is how to fix the optimal cell dose to be administered to the patients and which is the best administration route, considering together the safety aspects and the efficacy objectives. When the protocol was conceived, the dose to be given was established based on several considerations. In particular, although there were data showing that MSCs in PD patients do not differ from those of healthy subjects in terms of phenotype, morphology and ability to differentiate into other cells [58], a preliminary study was conducted in PSP patients, to check the bone marrow function and MSC yield and to establish how many cells could be realistically produced for administration. The elements that have been used for the definition of the cell dose were the quaantity of MSCs that was obtained from maximum $30 \mathrm{~mL}$ of bone marrow and the cell dose that was given in the three protocols that were previously performed with MSC in parkinsonisms $\left(1-2 \times 10^{6} / \mathrm{kg}\right)$. Thus, the cell dose was fixed at $1.5 \pm$ $0.5 \times 10^{6} / \mathrm{kg}$. Regarding the route of administration, several possibilities were considered. Systemically injected MSC undergo intra-pulmonary cell trapping [66] and therefore only a limited amount of cells might home to the brain. Stereotaxic-guided intra-striatal implantation was excluded in consideration of the pathologic characteristics of PSP that has a much wider distribution compared to classic Parkinson disease and for safety concerns, since there are several evidences that intra-striatal cell administration may cause harm and reduce efficacy by evoking a local cellular immune response [67]. Therefore, we decided to use superselective arterial catheterization to implant stem cells throw the arteries that feed the brain regions affected by PSP to release in situ the highest concentration of MSC. This technique has been used in the three out of four previous clinical trial in parkinsonisms, with no major adverse events out of the report of asymptomatic microembolism. To minimize this risk, several precautions have been taken in our protocol during the preparation of the cell product such as dilution of the cells to less than $1 \times 10 \mathrm{E} 6$ cells $/ \mathrm{mL}$ and the addition of an anticoagulant (ACD-A) to the solution in which the cells are re-suspended before infusion.

In this study a "pure" control group treated with placebo solution administered by the same route in a doubleblinded manner is missing since this option was considered not acceptable by the ethical point of view by the investigators, given the potential harm of a cerebral artery catheterization procedure that is not justified by a potential benefit. Nevertheless, the patients enrolled in the control harm receive a simulated arterial catheterization and administration procedure and the neurologist and the neuro-radiologist who perform the follow-up evaluation are blinded. In this way, we exclude the placebo effect with the best precision.

In conclusions, the presented protocol is the first attempt to understand if MSC can be safely administered and can exert a beneficial effect in PSP patients. We believe that the results of this trial will help to improve the knowledge around the neuroprotective properties of MSC that might be exploited in other several neurodegenerative disorders.

\section{Abbreviations}

BDNF: Brain-derived neurotrophic factor; BNGF: Basic nerve growth factor: CNTF: Ciliary neuronotrophic factor; DSM: Diagnostic and statistical manual of mental disorders; EMG: Electromyography; FDG: 18 F-Fluoro-deoxyglucose; GCP: Good clinical practice; GDNF: Glial cell-derived neurotrophic factor; GMP: Good manufacturing practice; IEC: Independent ethics committee; MDS: Movement disorder society; MMP: Matrix metalloproteinase; 
MMSE: Mini-mental state examination; MR: Magnetic resonance; MRI: Magnetic resonance imaging; MSC: Mesenchymal stem cells; NT-3: Neurotrophins-3; 6OHDA: 6-HydroxyDopamine; PD: Parkinson's disease; PET: Positron emission tomography; PSP: Progressive supranuclear palsy; ROM: Range of motion; QC: Quality control; SD: Standard deviation; SEADL: Schwab and England activities of daily living; SPECT: Single photon emission computed tomography; UPDRS: Unified Parkinson's disease rating scale.

\section{Competing interests}

The authors declare that they have no competing interests.

\section{Authors' contributions}

RG contributed to study design and to write the clinical protocol; specifically she designed the pre-clinical study, contributed to set up the procedures for mesenchymal stem cell GMP validation, production and quality controls and wrote the protocols and performed the submission of the trial to the regulatory authorities. MC: contributed to study design and to write the clinical protocol; specifically he defined the procedure for patient selection, clinical evaluation and follow-up. Ml contributed to study design and to write the clinical protocol; specifically he defined the procedure for cell administration. IUI contributed to study design and to write the clinical protocol; specifically he defined the procedure for the multifactorial movement analysis. TM contributed to design the pre-clinical study, set up the procedures for mesenchymal stem cell GMP validation and production. MV contributed to design the pre-clinical study, set up the procedures for mesenchymal stem cell GMP validation and quality control. EM contributed to set up the procedures for mesenchymal stem cell GMP validation and production. VB performed the ELISA assay and the real-time PCR studies. RB contributed to study design and to write the clinical protocol; specifically he defined the procedure for the PET analysis. AC took care of the bone marrow aspiration procedure and haematological patient assessment. NF took care of the bone marrow aspiration procedure and haematological patient assessment. LL contributed to study design and to the pre-clinical study. GP conceived the clinical trial, contributed to study design and to write the clinical protocol. All authors read and approved the final manuscript.

\section{Acknowledgments}

Associazione Italiana Parkinsoniani Fondazione Grigioni per il morbo di Parkinson supported the pre-clinical and the clinical protocol with a grant under the title "Validazione del protocollo clinico per l'autotrapianto di cellule staminali autologhe nei parkinsonismi". The study is also supported by Italian Ministry of Health (Fondi 5 per 1000 2013). We thank Dr. Jennifer Hartwig for the accurate English reduction of the clinical protocol. Finally, we thank all the patients and their families for participating to the study and for encouraging us to do this research.

\section{Author details}

${ }^{1}$ Cell Factory, Unit of Cell Therapy and Cryobiology, Fondazione IRCCS Ca' Granda Ospedale Maggiore Policlinico, Milano, Italy. ${ }^{2}$ Parkinson Center, Istituti Clinici di Perfezionamento, Milano, Italy. ${ }^{3}$ Interventional Neuroradiology Unit, Fondazione IRCCS Ca' Granda Ospedale Maggiore Policlinico, Milano, Italy. ${ }^{4}$ Klinik und Poliklinik für Neurologie, Universitätsklinikum Würzburg, Würzburg, Germany. ${ }^{5}$ Nuclear Medicine Unit, Fondazione IRCCS Ca' Granda Ospedale Maggiore Policlinico, Milano, Italy. ${ }^{6}$ Hematology and Transplantation Unit, Fondazione IRCCS Ca' Granda Ospedale Maggiore Policlinico and University of Milan, Milan, Italy.

\section{Received: 2 October 2013 Accepted: 26 December 2013}

Published: 17 January 2014

\section{References}

1. Nath U, Ben-Shlomo Y, Thomson RG, Morris HR, Wood NW, Lees AJ, Burn DJ: The prevalence of progressive supranuclear palsy (Steele-RichardsonOlszewski syndrome) in the UK. Brain 2001, 124:1438-1449.

2. Bower JH, Maraganore DM, McDonnell SK, Rocca WA: Incidence of progressive supranuclear palsy and multiple system atrophy in Olmsted County, Minnesota, 1976 to 1990. Neurology 1997, 49:1284-1288.

3. Ludolph AC, et al: Tauopathies with parkinsonism: clinical spectrum, neuropathologic basis, biological markers and treatment options. Eur J Neurol 2009, 16:297-309.

4. Litvan I, Agid Y, Calne D, Campbell G, Dubois B, Duvoisin RC, Goetz CG, Golbe LI, Grafman J, Growdon JH, Hallett M, Jankovic J, Quinn NP, Tolosa E,
Zee DS: Clinical research criteria for the diagnosis of progressive supranuclear palsy (Steele-Richardson-Olszewski syndrome): report of the NINDS-SPSP international workshop. Neurology 1996, 47:1-9.

5. Litvan I, Campbell G, Mangone CA, Verny M, McKee A, Chaudhuri KR, Jellinger K, Pearce RK, D'Olhaberriague L: Which clinical features differentiate progressive supranuclear palsy (Steele-RichardsonOlszewski syndrome) from related disorders? A clinicopathological study. Brain 1997, 120:65-74.

6. Karakaya T, Fußer F, Prvulovic D, Hampel H: Treatment options for tauopathies. Curr Treat Options Neurol 2012, 14:126-36.

7. Zampieri C, Di Fabio RP: Progressive supranuclear palsy: disease profile and rehabilitation strategies. Phys Ther 2006, 86:870-880.

8. Nath U, Ben-Shlomo Y, Thomson RG, Lees AJ, Burn DJ: Clinical features and natural history of pregressive supranuclear palsy. A clinical cohort study. Neurology 2003, 60:910-916.

9. Litvan I, Bhatia KP, Burn DJ, Goetz CG, Lang AE, McKeith I, Quinn N, Sethi KD, Shults C, Wenning GK, Movement Disorders Society Scientific Issues Committee: Movement Disorders Society Scientific Issues Committee report: SIC Task Force appraisal of clinical diagnostic criteria for Parkinsonian disorders. Mov Disord 2003, 18:467-486.

10. Golbe LI: Neurodegeneration in the age of molecular biology. BMJ 2002, 324:1467-1468.

11. Ferrer I, López-González I, Carmona M, Arregui L, Dalfó E, Torrejón-Escribano B, Diehl R, Kovacs GG: Glial and neuronal tau pathology in tauopathies: characterization of disease-specific phenotypes and tau pathology progression. J Neuropathol Exp Neurol 2014, 73:81-97.

12. Ghawche F, Durif F: Dopaminergic treatment and parkinsonian syndromes. Rev Neurol 2003, 159:3S83-3S86.

13. Hilker R, Benecke R, Deuschl G, Fogel W, Kupsch A, Schrader C, Sixel-Döring F, Timmermann L, Volkmann J, Lange M, German Deep Brain Stimulation Association: Deep brain stimulation for Parkinson's disease. Consensus recommendations of the German Deep Brain Stimulation Association. Nervenarzt 2009, 80:646-655.

14. Silberstein P, Bittar RG, Boyle R, Cook R, Coyne T, O'Sullivan D, Pell M, Peppard R, Rodrigues J, Silburn P, Stell R, Watson P, Australian DBS Referral Guidelines Working Group: Deep brain stimulation for Parkinson's disease: Australian referral guidelines. J Clin Neurosci 2009, 16:1001-1008.

15. von Bahr L, Sundberg B, Lönnies L, Sander B, Karbach H, Hägglund H, Ljungman P, Gustafsson B, Karlsson H, Le Blanc K, Ringdén O: Long-term complications, immunologic effects, and role of passage for outcome in mesenchymal stromal cell therapy. Biol Blood Marrow Transplant 2012, 18:557-564.

16. Wang S, Cheng H, Dai G, Wang X, Hua R, Liu X, Wang P, Chen G, Yue W, An $Y$ : Umbilical cord mesenchymal stem cell transplantation significantly improves neurological function in patients with sequelae of traumatic brain injury. Brain Res 2013. Epub ahead of print.

17. Jiang PC, Xiong WP, Wang G, Ma C, Yao WQ, Kendell SF, Mehling BM, Yuan XH, Wu DC: A clinical trial report of autologous bone marrow-derived mesenchymal stem cell transplantation in patients with spinal cord injury. Exp Ther Med. 2013, 6:140-146.

18. Tzouvelekis A, Paspaliaris V, Koliakos G, Ntolios P, Bouros E, Oikonomou A, Zissimopoulos A, Boussios N, Dardzinski B, Gritzalis D, Antoniadis A, Froudarakis $M$, Kolios $G$, Bouros D: A prospective, non-randomized, no placebo-controlled, phase lb clinical trial to study the safety of the adipose derived stromal cells-stromal vascular fraction in idiopathic pulmonary fibrosis. J Trans/ Med 2013, 11:171.

19. Yamada Y, Nakamura S, Ito K, Umemura E, Hara K, Nagasaka T, Abe A, Baba S, Furuichi $Y$, Izumi Y, Klein OD, Wakabayashi T: Injectable bone tissue engineering using expanded mesenchymal stem cells. Stem Cells 2013, 31:572-80.

20. Blum $\mathrm{R}$, Konnerth $\mathrm{A}$ : Neurotrophin-mediated rapid signaling in the central nervous system: mechanisms and functions. Physiology 2005, 20:70-8.

21. Guillin O, Diaz J, Carroll P, Griffon N, Schwartz JC, Sokoloff P: BDNF controls dopamine D3 receptor expression and triggers behavioural sensitization. Nature 2001, 411:86-9.

22. Airaksinen MS, Saarma M: The GDNF family: signalling, biological functions and therapeutic value. Nat Rev Neurosci 2002, 3:383-94.

23. Ugarte SD, Lin E, Klann E, Zigmond MJ, Perez RG: Effects of GDNF on 6OHDA-induced death in a dopaminergic cell line: modulation by inhibitors of PI3 kinase and MEK. J Neurosci Res 2003, 73:105-12.

24. Poteryaev D, Titievsky A, Sun YF, Thomas-Crusells J, Lindahl M, Billaud M, Arumäe U, Saarma M: GDNF triggers a novel ret-independent Src kinase 
family-coupled signaling via a GPI-linked GDNF receptor alpha1. FEBS Lett 1999, 463:63-6.

25. Besset $V$, Scott RP, Ibáñez CF: Signaling complexes and protein-protein interactions involved in the activation of the Ras and phosphatidylinositol 3-kinase pathways by the c-Ret receptor tyrosine kinase. J Biol Chem 2000, 275:39159-66.

26. Coulpier M, Anders J, Ibáñez CF: Coordinated activation of autophosphorylation sites in the RET receptor tyrosine kinase: importance of tyrosine 1062 for GDNF mediated neuronal differentiation and survival. J Biol Chem 2002, 277:1991-9.

27. Lin MN, Shang DS, Sun W, Li B, Xu X, Fang WG, Zhao WD, Cao L, Chen YH: Involvement of PI3K and ROCK signaling pathways in migration of bone marrow-derived mesenchymal stem cells through human brain microvascular endothelial cell monolayers. Brain Res 2013, 1513:1-8

28. Brazzini A, Cantella R, De la Cruz A, Yupanqui J, León C, Jorquiera T, Brazzini M, Ortega M, Saenz LN: Intraarterial autologous implantation of adult stem cells for patients with Parkinson disease. J Vasc Interv Radiol 2010, 21:443-451.

29. Bruno S, Camussi G: Role of mesenchymal stem cell-derived microvesicles in tissue repair. Pediatr Nephrol 2013, 28:2249-54.

30. Quattrone A, Nicoletti G, Messina D, Fera F, Condino F, Pugliese P, Lanza P, Barone P, Morgante L, Zappia M, Aguglia U, Gallo O: MR imaging index for differentiation of progressive supranuclear palsy from Parkinson disease and the Parkinson variant of multiple system atrophy. Radiology 2008, 246:214-21.

31. Goetz CG, Tilley BC, Shaftman SR, Stebbins GT, Fahn S, Martinez-Martin P, Poewe W, Sampaio C, Stern MB, Dodel R, Dubois B, Holloway R, Jankovic J, Kulisevsky J, Lang AE, Lees A, Leurgans S, LeWitt PA, Nyenhuis D, Olanow CW Rascol O, Schrag A, Teresi JA, van Hilten JJ, LaPelle N, Movement Disorder Society UPDRS Revision Task Force: Movement Disorder Society-sponsored revision of the Unified Parkinson's Disease Rating Scale (MDS-UPDRS): scale presentation and clinimetric testing results. Mov Disord 2008, 23:2129-70.

32. Goetz CG, Poewe W, Rascol O, Sampaio C, Stebbins GT, Counsell C, Giladi N, Holloway RG, Moore CG, Wenning GK, Yahr MD, Seidl L: Movement Disorder Society Task Force report on the Hoehn and Yahr staging scale: status and recommendations. Mov Disord 2004, 19:1020-8.

33. Golbe LI, Ohman-Strickland PA: A clinical rating scale for progressive supranuclear palsy. Brain 2007, 130:1152-65.

34. Streiner DL, Norman GR: Health measurement scales: a practical guide to their development and use. Oxford: Oxford University Press; 2003. doi:10.1093/ acprof:oso/9780199231881.001.0001. ISBN 9780199231881

35. Crenna P, Carpinella I, Lopiano L, Marzegan A, Rabuffetti M, Rizzone M, Lanotte M, Ferrarin M: Influence of basal ganglia on upper limb locomotor synergies. Evidence from deep brain stimulation and L-DOPA treatment in Parkinson's disease. Brain 2008, 131:3410-20.

36. Folstein MF, Folstein SE, McHugh PR: "Mini-mental state". A practical method for grading the cognitive state of patients for the clinician. J Psychiatr Res 1975, 12:189-98.

37. Jenkinson $C$, Fitzpatrick R: Cross-cultural evaluation of the short form 8-item Parkinson's disease Questionnaire (PDQ-8): results from America, Canada, Japan, Italy and Spain. Parkinsonism Relat Disord 2007, 13:22-28.

38. National Cancer Institute Common Toxicity Criteria Manual '(CTCAE v 4.0). available at http://ctep.cancer.gov/protocolDevelopment/ electronic_applications/ctc.htm\#ctc_mapping_docs.

39. Goetz CG, Olanow CW, Koller WC, Penn RD, Cahill D, Morantz R, Stebbins G, Tanner CM, Klawans HL, Shannon KM: Multicenter study of autologous adrenal medullary transplantation to the corpus striatum in patients with advanced Parkinson's disease. N Engl J Med 1989, 320:337-341.

40. Pezzoli G, Motti E, Zecchinelli A, Ferrante C, Silani V, Falini A, Pizzuti A, Mulazzi D, Baratta $P$, Vegeto A: Adrenal medulla autograft in 3 parkinsonian patients: results using two different approaches. Prog Brain Res 1990, 82:677-682.

41. Olanow CW, Koller W, Goetz CG, Stebbins TG, Cahill DW, Gauger LL, Morantz R, Penn RD, Tanner CM, Klawans HL, Shannon KM, Comella CL, Witt T: Autologous transplantation of adrenal medulla in Parkinson's disease: 18-month results. Arch Neurol 1990, 47:1286-1289.

42. Fazzini E, Dwork AJ, Blum C, Burke R, Cote L, Goodman RR, Jacobs TP, Naini AB, Pezzoli G, Pullman S, Solomon RA, Truong D, Weber CJ, Fahn S: Stereotaxic implantation of autologous adrenal medulla into caudate nucleus in four patients with parkinsonism. One year follow-up. Arch Neurol 1991, 48:813-820.
43. Fazzini E: Transplantation in the treatment of paralysis agitans (Parkinson's disease). J Am Osteopath Assoc 1992, 92:1255-1260.

44. Freed CR, Greene PE, Breeze RE, Tsai WY, DuMouchel W, Kao R, Dillon S, Winfield H, Culver S, Trojanowski JQ, Eidelberg D, Fahn S: Transplantation of embryonic dopamine neurons for severe Parkinson's disease. New Engl J Med 2001, 344:710-719.

45. Ma Y, Feigin A, Dhawan V, Fukuda M, Shi Q, Greene P, Breeze R, Fahn S, Freed $C$, Eidelberg D: Dyskinesia after fetal cell transplantation for parkinsonism: PET study. Ann Neurol 2002, 52:628-634.

46. Politis M, Wu K, Loane C, Quinn NP, Brooks DJ, Rehncrona S, Bjorklund A, Lindvall O, Piccini P: Serotonergic neurons mediate dyskinesia side effects in Parkinson's patients with neural transplants. Sci Transl Med 2010, 2:38-46.

47. Lindvall $\mathrm{O}$, Kokaia Z: Prospects of stem cell therapy for replacing dopamine neurons in Parkinson's disease. Trends Pharmacol Sci 2009, 30:260-7.

48. Olanow CW, Kordower $\mathrm{JH}$, Lang AE, Obeso JA: Dopaminergic transplantation for Parkinson's disease: current status and future prospects. Ann Neurol 2009, 66:591-6.

49. Arias-Carrion O, Yuan TF: Autologous neural stem cell transplantation: a new treatment option for Parkinson's disease? Med Hypotheses 2009, 73:757-759.

50. Eglitis MA, Mezey E: Hematopoietic cells differentiate into both microglia and macroglia in the brains of adult mice. Proc Natl Acad Sci 1997, 94:4080-4085.

51. Mezey E, Chandross KJ, Harta G, Maki RA, McKercher SR: Turning blood into brain: cells bearing neuronal antigens generated in vivo from bone marrow. Science 2000, 290:1779-1782.

52. Cogle CR, Yachnis AT, Laywell ED, Zander DS, Wingard JR, Steindler DA, Scott EW: Bone marrow transdifferentiation in brain after transplantation: a retrospective study. Lancet 2004, 363:1432-7.

53. Cova L, Bossolasco P, Armentero MT, Diana V, Zennaro E, Mellone M, Calzarossa C, Cerri S, Deliliers GL, Polli E, Blandini F, Silani V: Neuroprotective effects of human mesenchymal stem cells on neural cultures exposed to 6-hydroxydopamine: implications for reparative therapy in Parkinson's disease. Apoptosis 2012, 17:289-304.

54. Cova L, Armentero MT, Zennaro E, Calzarossa C, Bossolasco P, Busca G, Lambertenghi Deliliers G, Polli E, Nappi G, Silani V, Blandini F: Multiple neurogenic and neurorescue effects of human mesenchymal stem cell after transplantation in an experimental model of Parkinson's disease. Brain Res 2010, 1311:12-27.

55. Blandini F, Cova L, Armentero MT, Zennaro E, Levandis G, Bossolasco P, Calzarossa C, Mellone M, Giuseppe B, Deliliers GL, Polli E, Nappi G, Silani V: Transplantation of undifferentiated human mesenchymal stem cells protects against 6-hydroxydopamine neurotoxicity in the rat. Cell Transplant 2010:203-17.

56. Lee PH, Park HJ: Bone-marrow-derived mesenchymal stem cell therapy as a candidate disease-modifying strategy in Parkinson's disease. Multiple system atrophy. J Clin Neurol 2009, 5:1-10.

57. Giordano A, Galderisi U, Marino IR: From the laboratory bench to the patient's bedside: an update on clinical trials with mesenchymal stem cells. J Cell Physiol 2007, 211:27-35.

58. Zhang Z, Wang X, Wang S: Isolation and characterization of mesenchymal stem cells derived from bone marrow of patients with Parkinson's disease. In Vitro Cell Dev Biol Anim 2008, 44(5-6):169-77.

59. Park HJ, Lee PH, Bang OY, Lee G, Ahn YH: Mesenchymal stem cells therapy exerts neuroprotection in a progressive animal model of Parkinson's disease. J Neurochem 2008, 107:141-151.

60. Kim YJ, Park HJ, Lee G, Bang OY, Ahn YH, Joe E, Kim HO, Lee PH: Neuroprotective effects of human mesenchymal stem cells on dopaminergic neurons through anti-inflammatory action. Glia 2009, 57:13-23.

61. Jin GZ, Cho SJ, Choi EG, Lee YS, Yu XF, Choi KS, Yee ST, Jeon JT, Kim MO, Kong IK: Rat mesenchymal stem cells increase tyrosine hydroxylase expressioni and dopamine content in ventral mesencephalic cells in vitro. Cell Biol Int 2008, 32(11):1433-8.

62. Sadan O, Bahat-Stromza M, Barhum Y, Levy YS, Pisnevsky A, Peretz H, llan AB, Bulvik S, Shemesh N, Krepel D, Cohen Y, Melamed E, Offen D: Protective effects of neurotrophic factor-secreting cells in a 6-OHDA rat model of Parkinson disease. Stem Cells Dev 2009, 18(8):1179-90.

63. Lee PH, Kim JW, Bang OY, Ahn YH, Joo IS, Huh K: Autologous mesenchymal stem cell therapy delays the progression of neurological deficits in patients with multiple system atrophy. Clin Pharmacol Ther 2008, 83:723-730.

64. Lee PH, Lee JE, Kim HS, Song SK, Lee HS, Nam HS, Cheong JW, Jeong Y, Park HJ, Kim DJ, Nam CM, Lee JD, Kim HO, Sohn YH: A randomized trial of 
mesenchymal stem cells in multiple system atrophy. Ann Neurol 2012, 72:32-40.

65. Venkataramana NK, Kumar SK, Balaraju S, Radhakrishnan RC, Bansal A, Dixit A, Rao DK, Das M, Jan M, Gupta PK, Totey SM: Open-labeled study of unilateral autologous bone-marrow-derived mesenchymal stem cell transplantation in Parkinson's disease. Transl Res 2010, 155:62-70.

66. Everaert BR, Bergwerf I, De Vocht N, Ponsaerts P, Van Der Linden A, Timmermans JP, Vrints CJ: Multimodal in vivo imaging reveals limited allograft survival, intrapulmonary cell trapping and minimal evidence for ischemia-directed bone marrow-derived stromal cell homing. BMC Biotechnol 2012, 12:93.

67. Camp DM, Loeffler DA, Farrah DM, Borneman JN, LeWitt PA: Cellular immune response to intrastriatally implanted allogeneic bone marrow stromal cells in a rat model of Parkinson's disease. J Neuroinflammation 2009, 6:17.

doi:10.1186/1479-5876-12-14

Cite this article as: Giordano et al:: Autologous mesenchymal stem cell therapy for progressive supranuclear palsy: translation into a phase I controlled, randomized clinical study. Journal of Translational Medicine 2014 12:14.

\section{Submit your next manuscript to BioMed Central and take full advantage of:}

- Convenient online submission

- Thorough peer review

- No space constraints or color figure charges

- Immediate publication on acceptance

- Inclusion in PubMed, CAS, Scopus and Google Scholar

- Research which is freely available for redistribution 